\title{
Loss of NEDD4 causes complete XY gonadal sex reversal
} in mice

\author{
Simon P. Windley (D) ${ }^{1}$, Chloé Mayère ${ }^{2}$, Alice E. McGovern ${ }^{1}$, Natasha L. Harvey ${ }^{3}$, Serge Nef ${ }^{2}$, Quenten Schwarz ${ }^{3}$, Sharad Kumar (D) $^{3}$ and \\ Dagmar Wilhelm (D) ${ }^{1 凶}$
}

(c) Crown 2022

Gonadogenesis is the process wherein two morphologically distinct organs, the testis and the ovary, arise from a common precursor. In mammals, maleness is driven by the expression of Sry. SRY subsequently upregulates the related family member Sox 9 which is responsible for initiating testis differentiation while repressing factors critical to ovarian development such as FOXL2 and $\beta$-catenin. Here, we report a hitherto uncharacterised role for the ubiquitin-protein ligase NEDD4 in this process. XY Nedd4-deficient mice exhibit complete male-to-female gonadal sex reversal shown by the ectopic upregulation of Fox/2 expression at the time of gonadal sex determination as well as insufficient upregulation of Sox9. This sex reversal extends to germ cells with ectopic expression of SYCP3 in XY Nedd4-/- germ cells and significantly higher Sycp3 transcripts in XY and XX Nedd4-deficient mice when compared to both XY and XX controls. Further, Nedd4-/- mice exhibit reduced gonadal precursor cell formation and gonadal size as a result of reduced proliferation within the developing gonad as well as reduced $\mathrm{Nr} 5 \mathrm{a} 1$ expression. Together, these results establish an essential role for NEDD4 in XY gonadal sex determination and development and suggest a potential role for NEDD4 in orchestrating these cell fate decisions through the suppression of the female pathway to ensure proper testis differentiation.

Cell Death and Disease (2022)13:75; https://doi.org/10.1038/s41419-022-04519-z

\section{INTRODUCTION}

Gonadogenesis is a unique process wherein two morphologically distinct organs, the testis and the ovary, arise from a common precursor. Established on the ventromedial side of the mesonephros, this shared anlage develops as a thickening of the epithelium, which proliferates to give rise to the bipotential genital ridges. This process begins as early as 10.0 days post coitum ( $\mathrm{dpc}$ ) in mice with the expression of GATA4, which is quickly followed by expression of nuclear receptor subfamily 5 group A member 1, Nr5a1 (ref. [1]).

Maleness is determined upon expression of the sex-determining region on the $Y$ chromosome (Sry), which is expressed in Sertoli cell precursors starting in the centre of the gonad at $10.5 \mathrm{dpc}$ in mice, before spreading in a centre-to-pole fashion. Sry expression is fleeting, however, with peak expression observed at $11.5 \mathrm{dpc}$, before being downregulated, and becoming all but absent by $12.5 \mathrm{dpc}$, just 24 hours later $[2,3]$. Following this, SRY upregulates the SRY-box containing gene 9 (Sox9) and the testis programme is initiated [4]. SRY and SOX9 are both necessary and sufficient in determining the male fate with ablation of these factors resulting in male-to-female sex reversal in $\mathrm{XY}$ mice $[5,6]$ and ectopic expression in $\mathrm{XX}$ gonads leading to female-to-male sex reversal [7, 8].

Antagonism between testicular and ovarian promoting pathways exists and as such the testicular phenotype must be actively maintained in the XY gonad while simultaneously repressing proovarian pathways. In this way, ectopic strengthening of the ovarian pathway in XY gonads can result in male-to-female sex reversal as seen in mice over-expressing the pro-ovarian transcription factors FOXL2 (ref. [9]) and CTNNB1 (beta-catenin) [10], owing to the ability of these factors to suppress the testis programme [10-12]. While many factors critical to this process have been identified, the molecular mechanisms driving mammalian sex determination and gonadal development remain incompletely understood. Indeed, while our knowledge of sex determination and gonad development is biased towards the roles of transcription factors and signalling cascades [13] an essential role for post-translational modifications in these processes is becoming increasingly apparent [14-16].

One such modification, ubiquitination, is a process in which the 8.5 kilo Dalton protein ubiquitin is covalently added to protein substrates, enabling the regulation of protein stability and function [17]. The neural precursor cell expressed developmentally downregulated protein 4 (NEDD4) is a ubiquitin-protein ligase and the founding member of the NEDD4 family of HECT type ubiquitinprotein ligases, responsible for the transfer of ubiquitin onto protein substrates [18-20]. NEDD4 has been implicated in a wide array of developmental processes with loss of Nedd4 in mice resulting in embryonic lethality and growth restriction [21], abnormal cranial neural crest development [22], and perturbations to the developing cardiovascular, nervous and immune systems [23-25].

We have previously shown NEDD4 to be expressed at the time of murine testis differentiation and have identified potential substrates for NEDD4 in the developing testis [26]. Here, we report a role for

\footnotetext{
${ }^{1}$ Department of Anatomy \& Physiology, The University of Melbourne, Parkville 3010, Australia. ${ }^{2}$ Department of Genetic Medicine and Development, University of Geneva, 1211 Geneva, Switzerland. ${ }^{3}$ Centre for Cancer Biology, University of South Australia, Adelaide 5001, Australia. ${ }^{凶}$ email: dagmar.wilhelm@unimelb.edu.au Edited by Professor Mauro Piacentini
} 


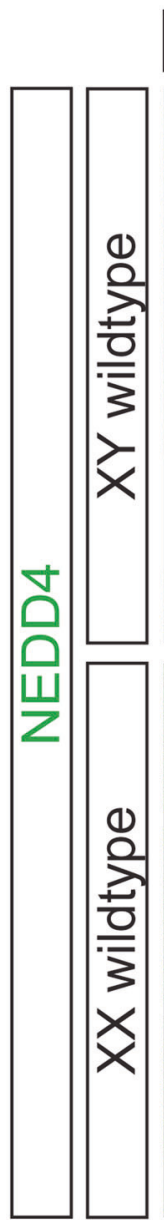

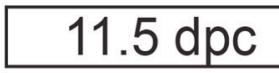
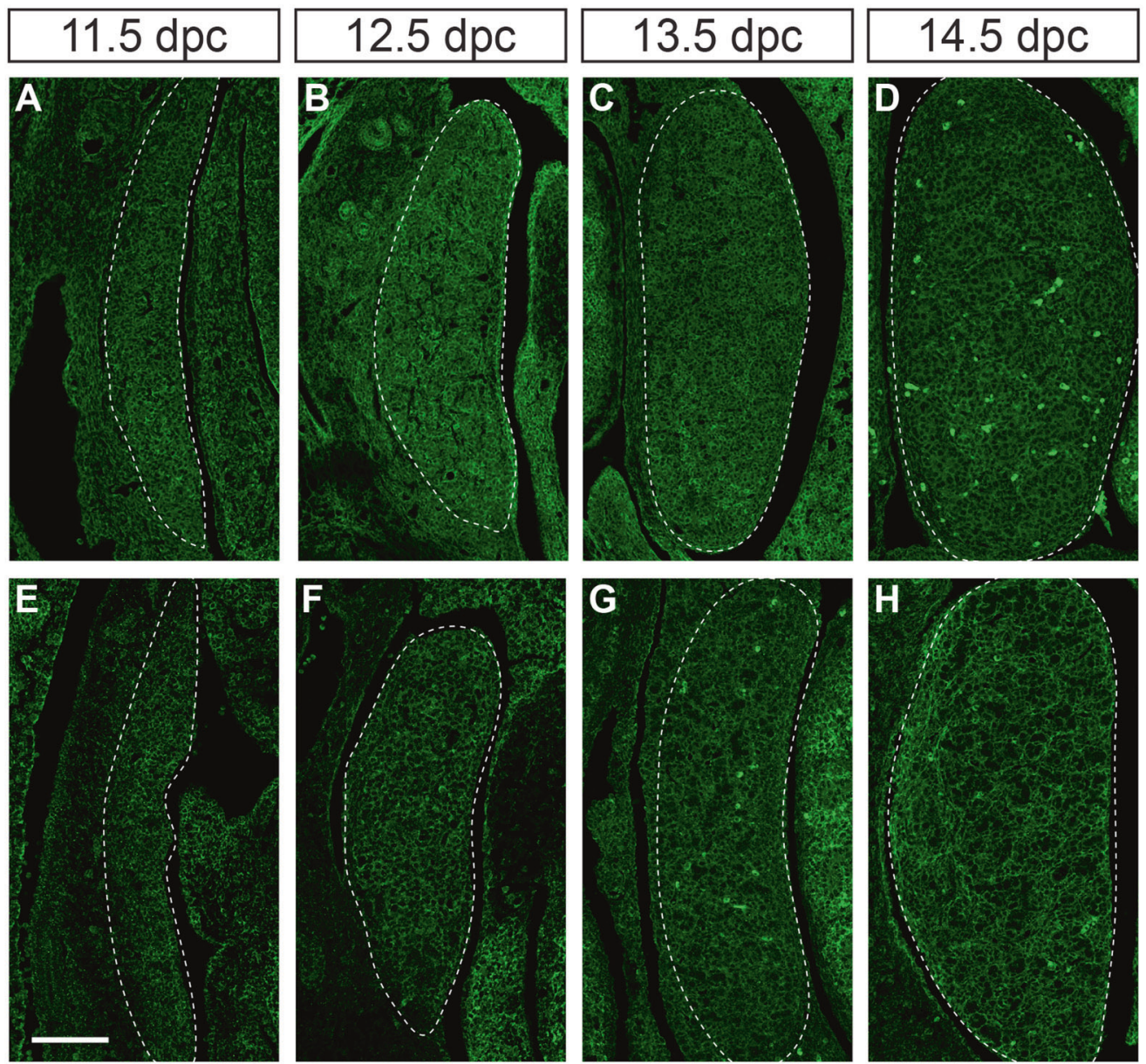

Fig. 1 NEDD4 is ubiquitously expressed in the developing XY gonad. Section immunofluorescence on XY (A-D) and XX (E-H) wildtype embryos from $11.5 \mathrm{dpc}$ to $14.5 \mathrm{dpc}$ stained for NEDD4 (green). Gonads are denoted by a white dotted line. The anterior pole of each gonad is positioned at the top of each panel. Scale bars $=100 \mu \mathrm{m}$.

NEDD4 in the developing gonads by characterising the gonadal phenotype of Nedd4-deficient mice. Our results reveal an uncharacterised role for NEDD4 in mouse development with Nedd4-deficient mice exhibiting complete male-to-female gonadal sex reversal.

\section{RESULTS \\ Homozygous deletion of Nedd4 causes complete male-to- female gonadal sex reversal}

We have previously shown that NEDD4 is expressed in all cells of the developing testis at $15.5 \mathrm{dpc}$, with its transcript detectable in both somatic and germ cells from 12.5 to $15.5 \mathrm{dpc}$ [26]. To extend this analysis and show in more detail the expression of NEDD4 protein during gonad differentiation, we performed immunofluorescence on paraffin sections of $X X$ and $X Y$ mouse embryonic gonads from $11.5 \mathrm{dpc}$, the time of gonadal sex determination, to $14.5 \mathrm{dpc}$, the time at which gonadal sex has become apparent. This analysis showed that NEDD4 is expressed ubiquitously throughout the developing gonads of both sexes at all time points analysed (Fig. 1) and, as expected, no NEDD4 was detected in Nedd4deficient (Nedd4-/-) mouse embryos (Supplementary Fig. S1).

Next, to characterise the role of Nedd4 in foetal gonads, we analysed gonads of Nedd4-/- at $14.5 \mathrm{dpc}$, a stage at which disruptions to gonadal sex determination and gonad differentiation are easily detectable by section immunofluorescence for testicular and ovarian markers. As expected, testes of XY littermate controls were round in appearance and showed DDX4 positive germ cells partitioned into testis cords throughout the gonad (Fig.
$2 \mathrm{~A}, \mathrm{~B})$. These testis cords also featured Sertoli cells, the testicular supporting cell lineage, as evidenced by the expression of SOX9 (Fig. 2A) and its downstream target AMH (Fig. 2C). CYP11A1 positive steroidogenic Leydig cells were present throughout the interstitium of XY control gonads (Fig. 2B) and FOXL2 positive granulosa cells, the ovarian supporting cell lineage, were all but absent (Fig. 2C). In contrast, XX control gonads were elongated with DDX4 positive cells located throughout the gonad (Fig. 2G, $H)$. XX control gonads showed a lack of SOX9 and AMH positive Sertoli cells (Fig. 2G, I) and CYP11A1 positive interstitial Leydig cells (Fig. $2 \mathrm{H}$ ) but had FOXL2 positive granulosa cells throughout the developing gonad (Fig. 2l), as expected. Analysis of XY Nedd4-/- gonads revealed no apparent testicular structures and were nearly indistinguishable from $X X$ controls (Fig. 2D-I). XY Nedd4-deficient gonads did not express the Sertoli cell markers SOX9 and AMH (Fig. 2D, F) nor the Leydig cell marker CYP11A1 (Fig. 2E). Instead, the ovarian granulosa cell marker FOXL2 was expressed throughout XY Nedd4-/- gonads (Fig. 2F) indicating that by $14.5 \mathrm{dpc} X Y$ Nedd4-/- mice exhibit complete male-to-female gonadal sex reversal. This was confirmed at the transcript level using quantitative RT-PCR (RT-qPCR), which showed that XY Nedd4-/- gonads had a complete loss of Nedd4 expression (Fig. 2J), a significant reduction in Sox9 and Amh (Fig. 2K, L) and a significant increase in Foxl2 (Fig. 2M) relative to $\mathrm{XY}$ controls, consistent with ovarian development at this time.

XX Nedd4-/- gonads appeared smaller than XX controls (Fig. 3), however despite the apparent size difference, XX Nedd4-/- gonads differentiated as expected, with FOXL2 positive somatic cells and 

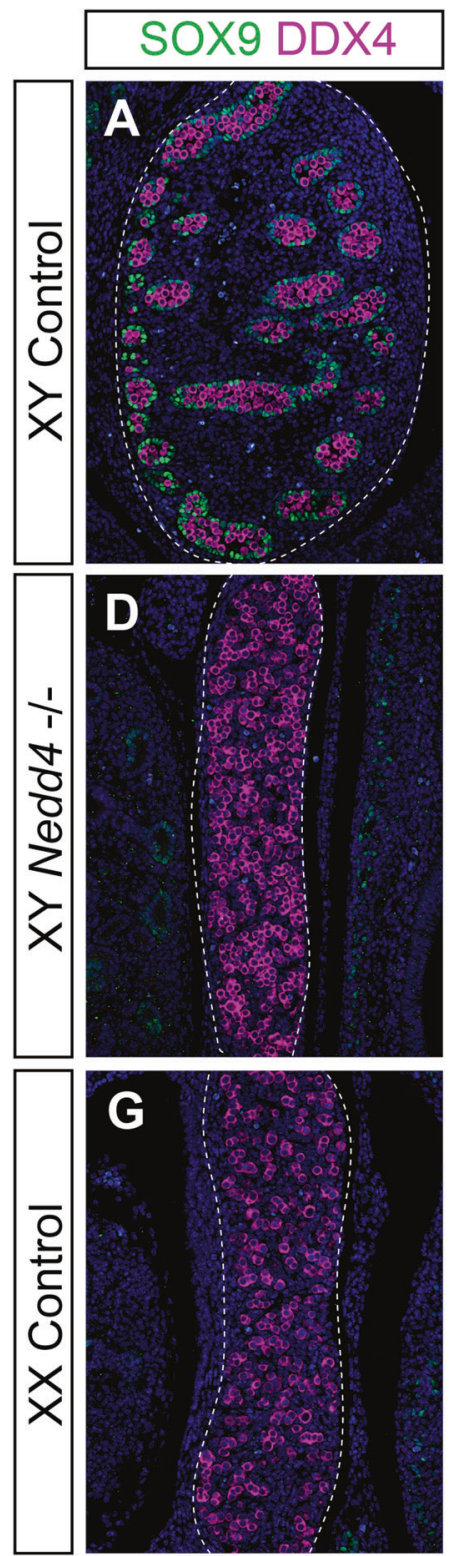
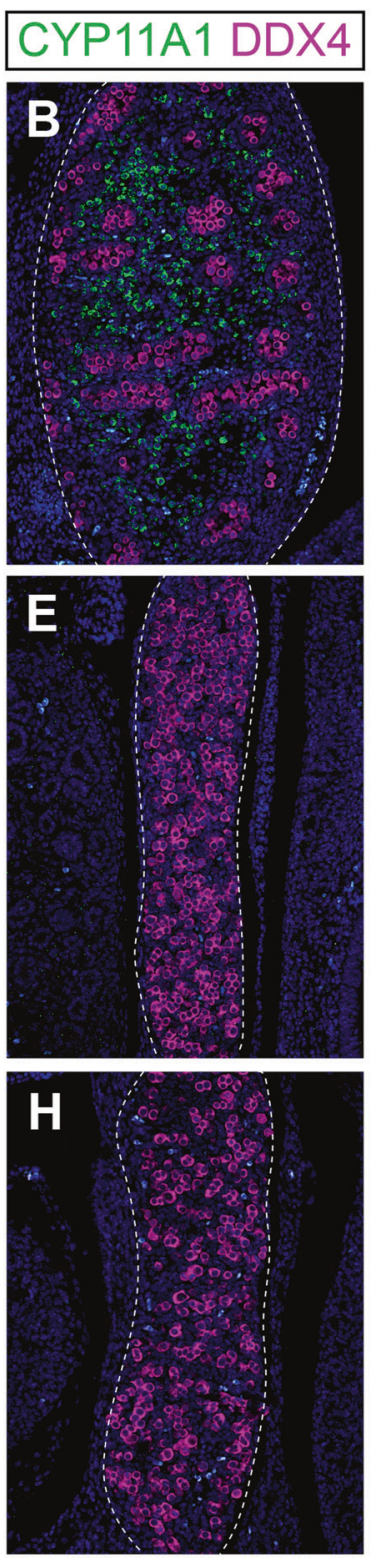
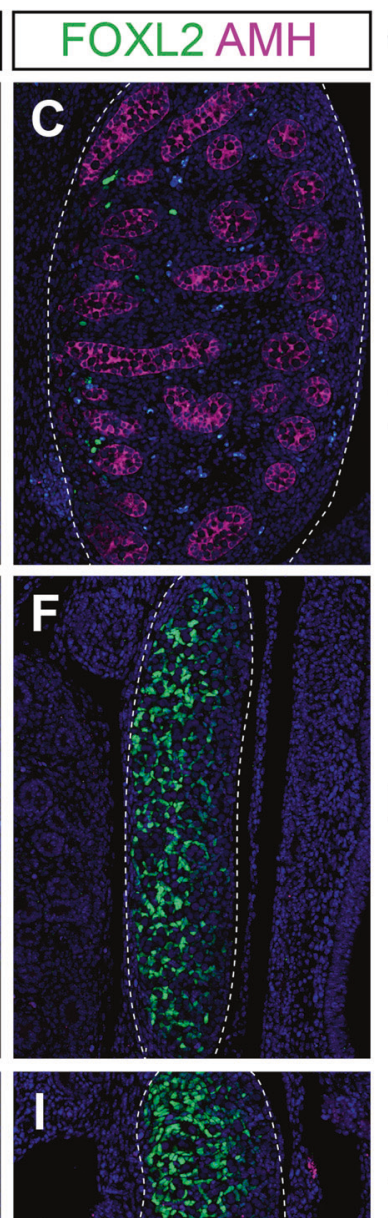

\section{$J$}
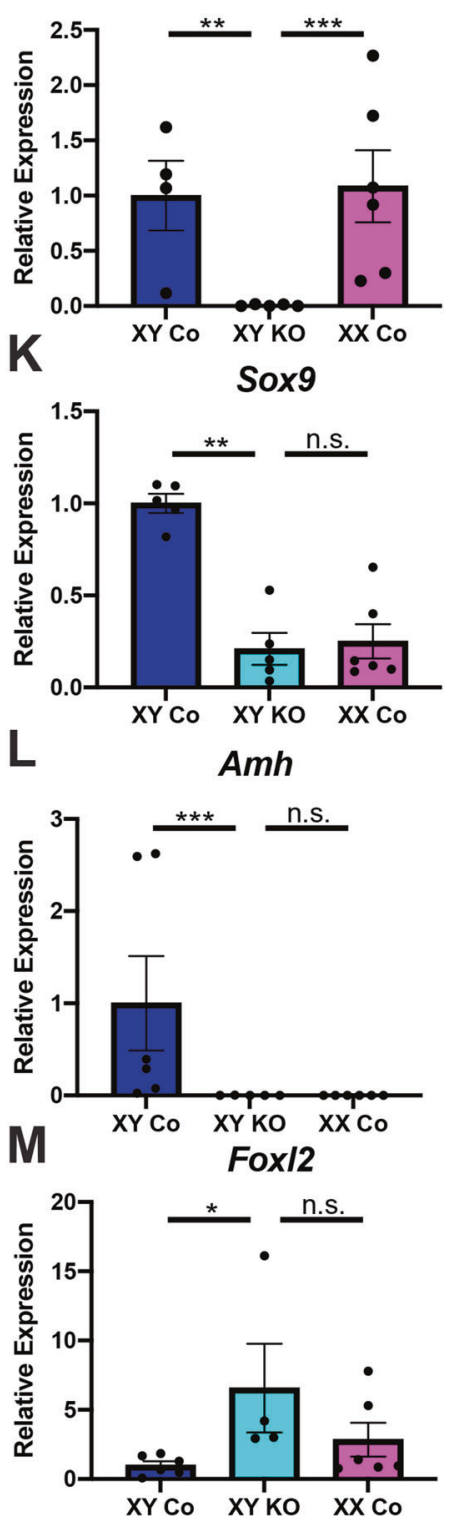

Fig. 2 Complete male-to-female sex reversal in XY Nedd4-/- mice. A-I Section immunofluorescence on 14.5 dpc XY Nedd4-/- embryos alongside XY and XX littermate controls stained for Sertoli cell markers SOX9 (green in A, D, G) and AMH (magenta in C, F, I), Leydig cell marker CYP11A1 (green in B, E, H), germ cell marker DDX4 (magenta in A, B, D, E, G, H) and granulosa cell marker FOXL2 (green in C, F, I). Gonads are denoted by a white dotted line. The anterior pole of each gonad is positioned at the top of each panel. Scale bars $=100 \mu \mathrm{m}$. RT-qPCR analyses of Nedd4 (J), Sox9 (K), Amh (L) and Foxl2 (M) expression at 14.5 dpc on XY Nedd4-/-gonads (KO) $(n=5), \mathrm{XY}$ controls (Co) $(n=6)$ and XX controls $(n=6)$. Values are expressed relative to the XY controls. Mean \pm SEM; $t$-test, n.s. not significant, ${ }^{*} p<0.05,{ }^{* *} p<0.01,{ }^{* * *} p<0.001$.

DDX4 positive germ cells present in knockout gonads at $15.5 \mathrm{dpc}$ (Fig. 3A). Further, RT-qPCR showed that Fox/2, Wnt4, Rspo1 and Axin2 transcript levels were unchanged in XX Nedd4-/- gonads at $14.5 \mathrm{dpc}$ (Fig. 3B-E), indicating that ovarian development proceeds normally in the absence of Nedd4.

Having shown that gonadal somatic cells are sex-reversed in $X Y$ Nedd4-/- gonads, we next investigated if this extends to primordial germ cells. A distinct difference in germ cell differentiation in the developing ovary compared to the testis is the down-regulation of pluripotency markers such as Pou5f1 and the entry into meiotic division beginning at $\sim 13.5 \mathrm{dpc}[27,28]$. As expected, section immunofluorescence analysis of embryonic gonads from $13.5 \mathrm{dpc}$ to $15.5 \mathrm{dpc}$ showed that $\mathrm{XY}$ control samples remained negative for the meiosis marker synaptonemal complex 3 (SYCP3) at all stages analysed (Fig. 4A-C). In contrast, XX controls expressed SYCP3 in a handful of DDX4 positive germ cells as early as $13.5 \mathrm{dpc}$, before being expressed in almost all germ cells by $15.5 \mathrm{dpc}$ (Fig. 4G-I).

Immunofluorescence analysis of Nedd4-/- embryos revealed that mutant gonads were capable of supporting entry into meiosis, with SYCP3 expression observed in a similar fashion to that seen in $X X$ control gonads for both XY (Fig. 4D-F) and XX (Fig. 4J-L) Nedd4-/embryos. RT-qPCR analysis confirmed these data with expression of the meiosis markers Stra8 (Fig. 4M) and Sycp3 (Fig. 4N) significantly higher, and expression of Cyp26b1 (Fig. 4O), which is expressed in Sertoli cells and is responsible for degrading retinoic acid in the testis at this time, as well as Pou5f1 (Fig. 4P) significantly lower in XY Nedd4-/- compared to XY control gonads. Interestingly, while there was no significant difference in transcript levels of Stra8, Pou5f1 and Cyp26b1 between XX controls and Nedd4-/- gonads of both genetic sexes (Fig. 4M, O, P), Sycp3 transcripts were significantly higher in $\mathrm{XY}$ 

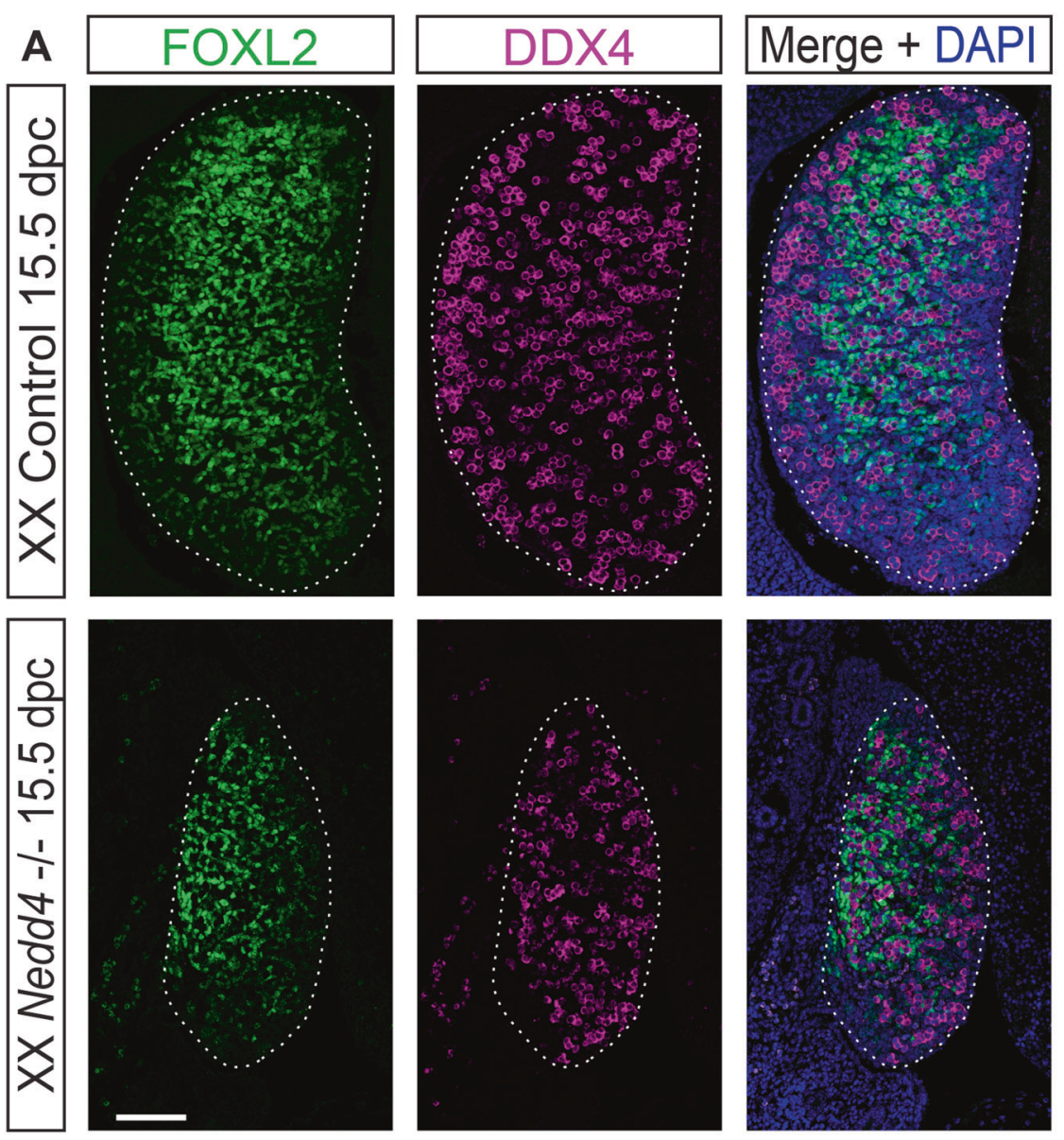

B

C

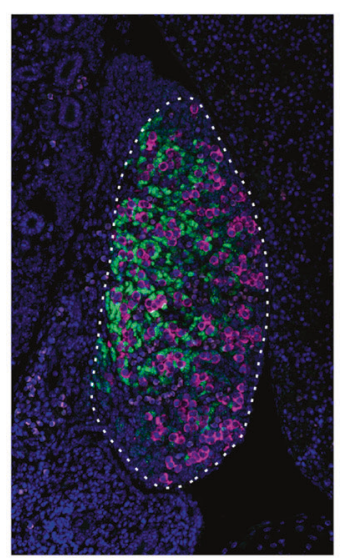

Foxl2
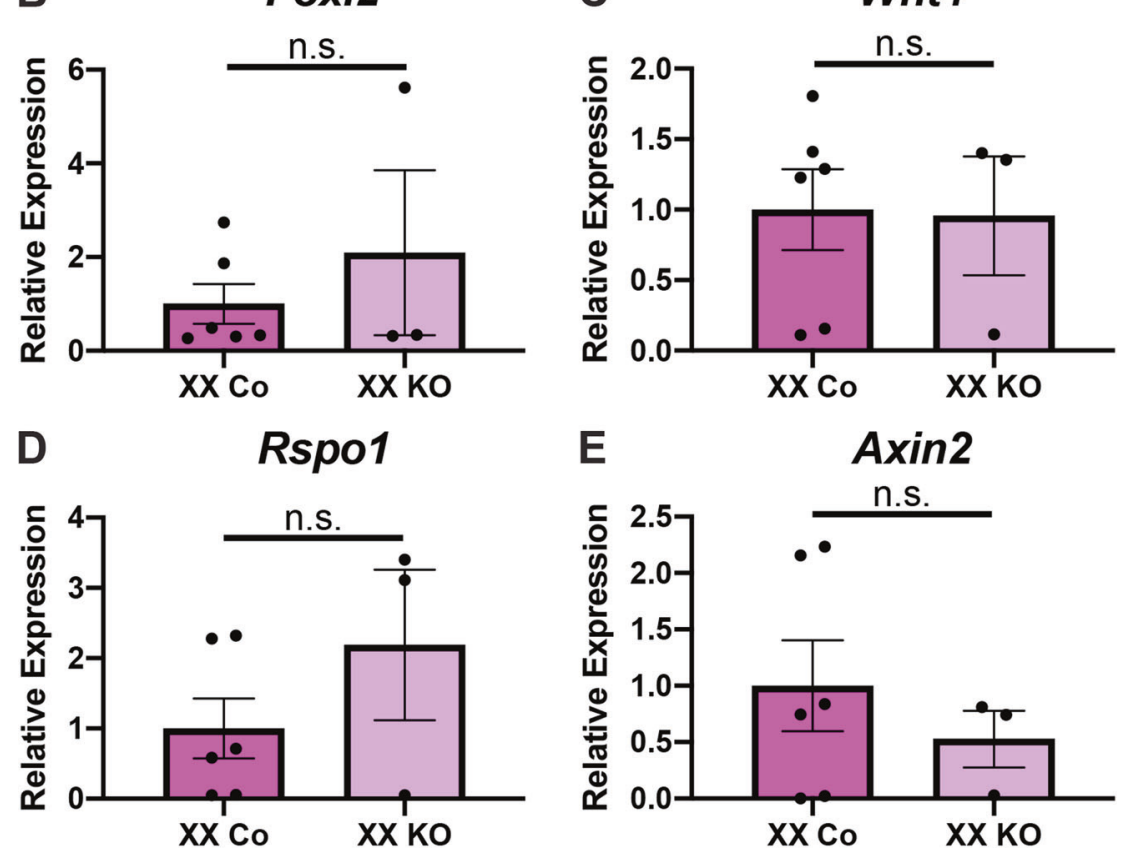

Fig. 3 Normal ovarian somatic cell development in XX Nedd4-/- mice. A Section immunofluorescence on 15.5 dpc XX Nedd4-/- embryos alongside XX littermate controls stained for ovarian somatic cells markers FOXL2 (green) and germ cell marker DDX4 (magenta). The anterior pole of each gonad is positioned at the top of each panel. Gonads are denoted by a white dotted line. Scale bars = $100 \mu \mathrm{m}$. (B-E) RT-qPCR analyses of Foxl2 (B), Wnt4 (C), Rspo1 (D) and Axin2 (E) expression at $14.5 \mathrm{dpc}$ on XX Nedd4-/- gonads (KO) $(n=3)$ and XX controls $(n=6)$. Values are expressed relative to the XX controls. Mean \pm SEM; $t$-test, n.s. not significant. 

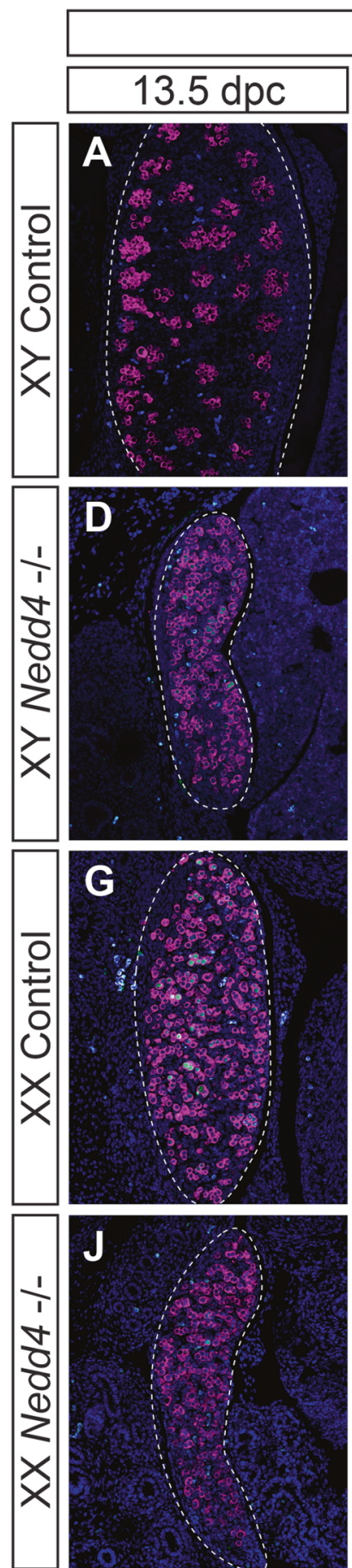

SYCP3 DDX4
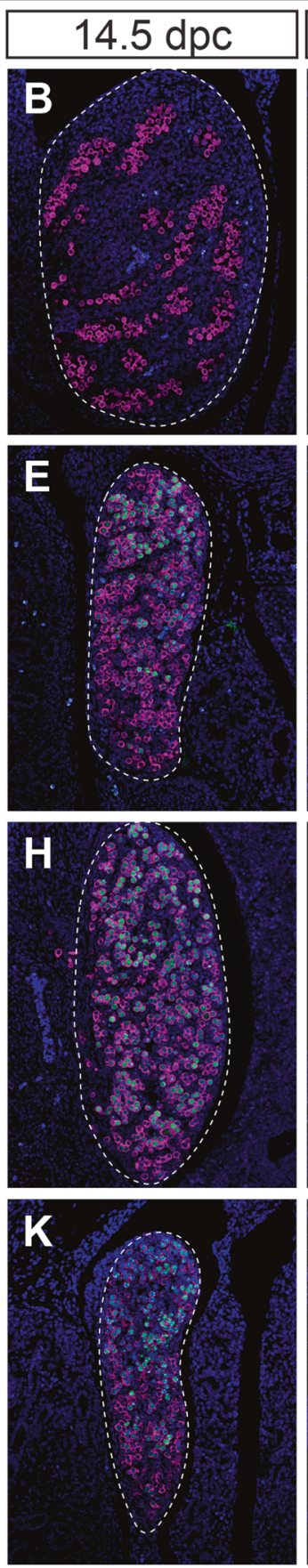
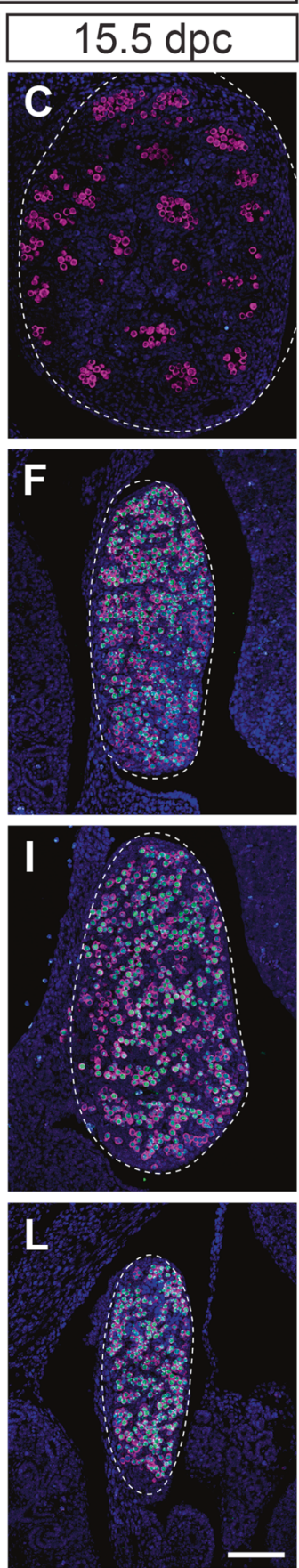
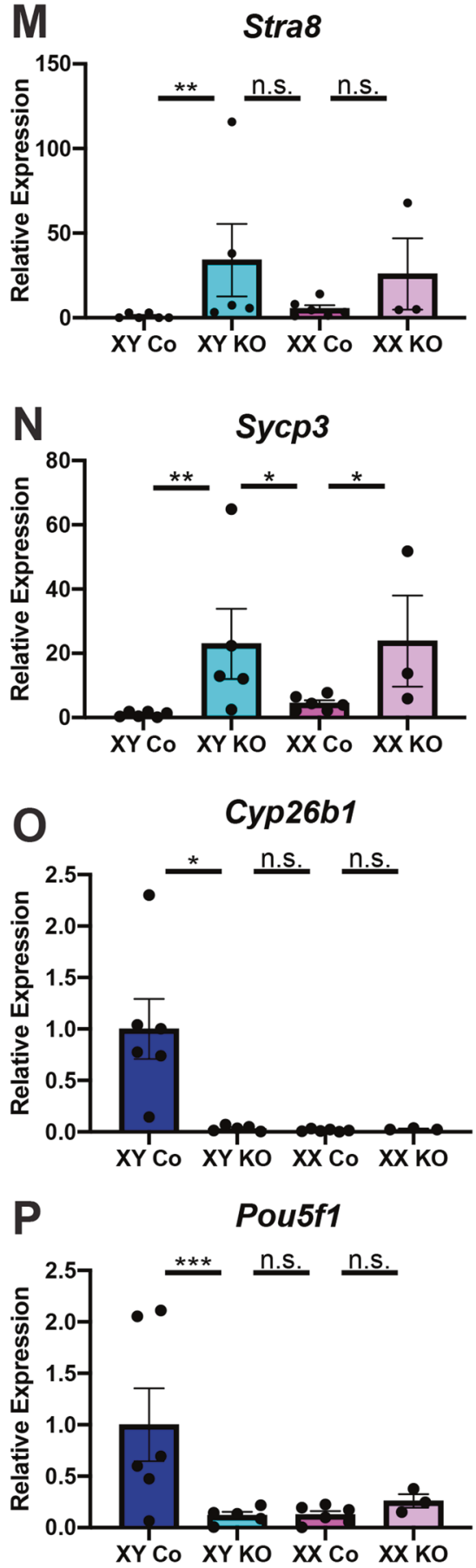

Fig. 4 Germ cells in XX Nedd4-/- mice enter meiosis. A-L Section immunofluorescence on $13.5 \mathrm{dpc} 14.5 \mathrm{dpc}$ and $15.5 \mathrm{dpc} X Y$ and $X X$ Nedd4-/- embryos alongside XY and XX littermate controls stained for germ cell marker DDX4 (magenta) and meiosis marker SYCP3 (green). Gonads are denoted by a white dotted line. The anterior pole of each gonad is positioned at the top of each panel. Scale bars $=100 \mu \mathrm{m}$. RTqPCR analyses of Stra8 (M), Sycp3 (N), Cyp26b1 (O) and Pou5f1 (P) expression at $14.5 \mathrm{dpc}$ on XY Nedd4-/-gonads (XY KO) ( $n=5)$, XX KO gonads $(n=3), \mathrm{XY}$ controls $(\mathrm{Co})(n=6)$ and XX controls $(n=6)$. Values are expressed relative to the XY controls. Mean \pm SEM; $t$-test; n.s. not significant, ${ }^{*} p<0.05,{ }^{* *} p<0.01,{ }^{* * *} p<0.001$.

and $X X$ knockout gonads than in both $X Y$ and $X X$ controls (Fig. $4 \mathrm{~N}$ ), perhaps indicative of a role for NEDD4 in suppressing Sycp3 and regulating entry into meiosis.

Delayed onset of the testis programme and ectopic FOXL2 in XY Nedd4-/- gonads

To determine the basis of the gonadal sex reversal observed in $\mathrm{XY}$ Nedd4-/- mice at $14.5 \mathrm{dpc}$, we next analyzed the gonadal phenotype of XY Nedd4-deficient mice between $11.5 \mathrm{dpc}$ and $12.5 \mathrm{dpc}$, the time in which gonadal sex is determined. Morphological analysis of mutant gonads at $11.5 \mathrm{dpc}$ (18 tail somites [ts]) revealed that XY Nedd4-/- gonads were substantially smaller than that of their $X Y$ control littermates, with the genital ridges appearing only a couple of cell layers thick (Fig. 5A, B).

Immunofluorescence for the testis-determining factor SRY revealed that in $\mathrm{XY}$ controls SRY protein was detected throughout 

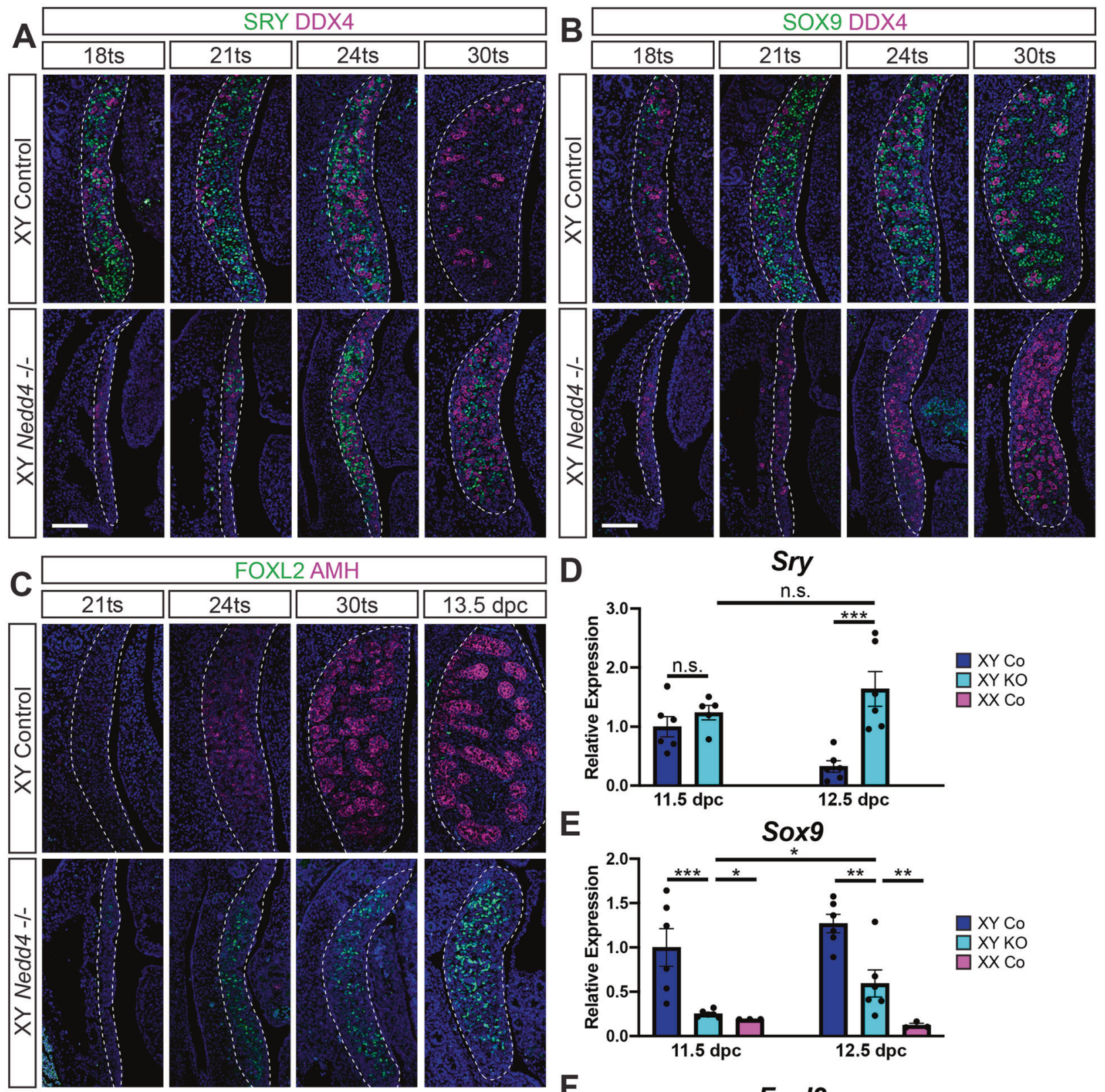

$\square X Y C o$
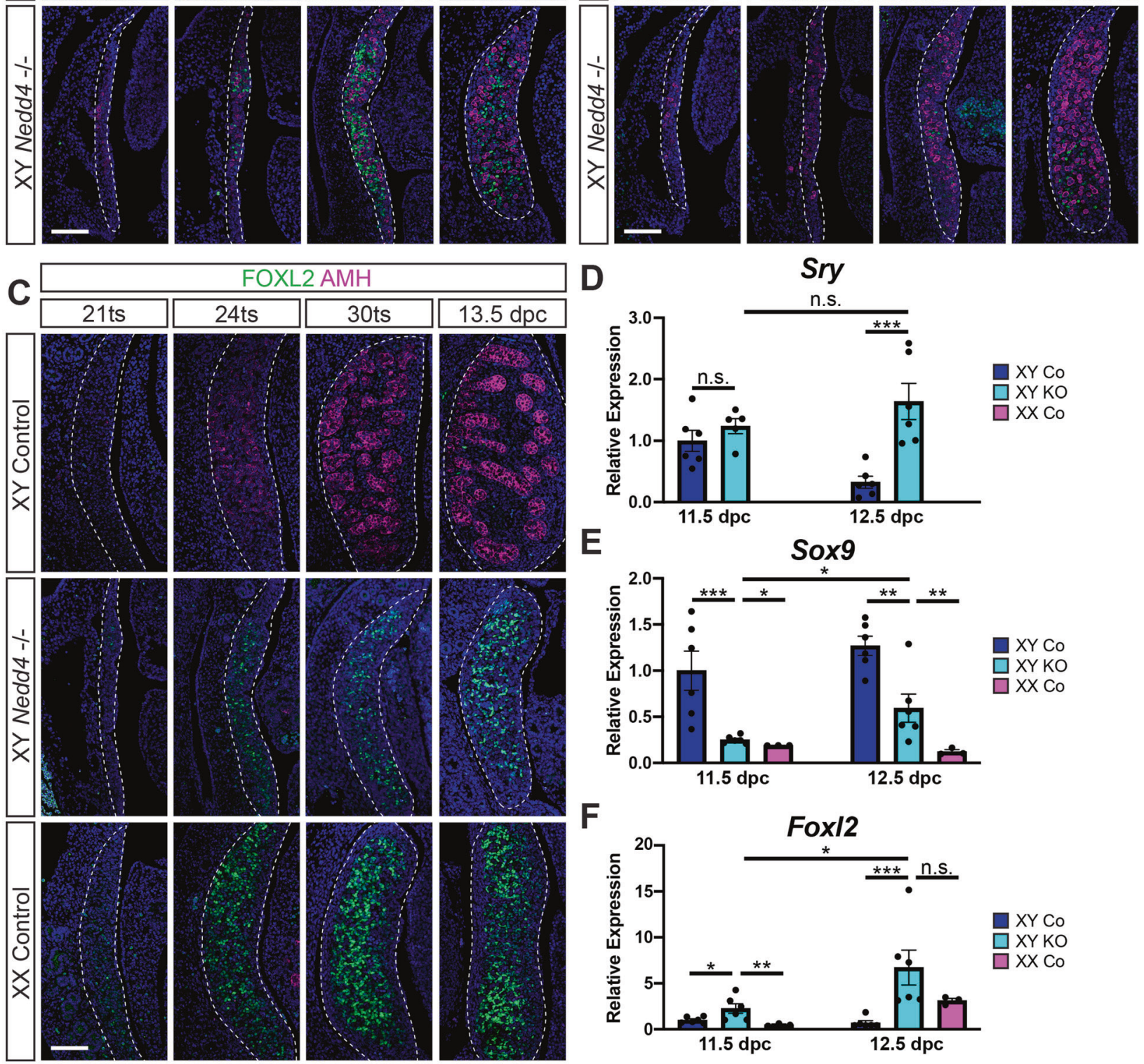

Fig. 5 Impaired Sertoli cell differentiation and ectopic FOXL2 in XY Nedd4-/- mice. Section immunofluorescence for the male sex determinant SRY (green) (A) and Sertoli cell marker SOX9 (green) (B) co-labelled with the germ cell marker DDX4 (magenta) on XY Nedd4-/embryos and XY wildtype controls between 18ts and 30ts. C Section immunofluorescence for the granulosa cell marker FOXL2 (green) and Sertoli cell marker AMH (magenta) on XY Nedd4-/- embryos alongside XY and XX controls between 21 ts and $13.5 \mathrm{dpc}$. The anterior pole of each gonad is positioned at the top of each panel. Gonads are denoted by a white dotted line. Scale bars $=100 \mu \mathrm{m}$. RT-qPCR analyses of Sry (D), Sox9 (E) and Fox/2 (F) expression at $11.5 \mathrm{dpc}$ (17-19ts - gonads + mesonephros) and $12.5 \mathrm{dpc}$ (gonads only) on XY Nedd4-/- (KO) (light blue; $n=6$ ), $\mathrm{XY}$ controls (Co) (dark blue; $n=6$ ) and XX controls (pink; $n=3$ ). Values are expressed relative to $11.5 \mathrm{dpc} X Y$ controls. Mean $\pm \mathrm{SEM}$; $t$-test; n.s. not significant, ${ }^{*} p<0.05,{ }^{* *} p<0.01,{ }^{* * *} p<0.001$. 
the gonads from 18ts (11.5 dpc) to 24ts but was absent at 30ts (12.5 dpc) (Fig. 5A, top panel). In contrast, SRY was not detected in XY Nedd4-/- gonads at 18ts but was subsequently expressed in increasing numbers of pre-Sertoli cells from 21 ts $(\sim 11.75 \mathrm{dpc})$ to 24ts $(12.0 \mathrm{dpc}$ ), and was still expressed at 30ts (Fig. 5A, bottom panel), indicating a delay in SRY expression in XY Nedd4-deficient mice when compared to $X Y$ control littermates.

Interestingly, quantification of Sry mRNA revealed no significant difference between XY Nedd4-/- mice and XY controls at $11.5 \mathrm{dpc}$ (17-19ts) (Fig. 5D), despite the stark contrast in SRY protein at this stage (Fig. 5A), perhaps indicative of post-transcriptional or posttranslational control of the male sex determinant. Consistent with SRY protein expression, however, while Sry mRNA was significantly downregulated by $12.5 \mathrm{dpc}$ in XY controls, Sry mRNA were maintained in XY Nedd4-/- gonads over this time and was significantly higher than Sry mRNA in XY control gonads at this stage (Fig. 5D).

We next analysed the expression of SOX9, the principal target of SRY, itself sufficient and necessary for testis differentiation $[5,6,8]$. While SOX9 positive Sertoli cells were apparent in XY controls at $18 \mathrm{ts}$, increased in numbers by 21 ts and began to coalesce to form testis cords by 30ts (Fig. 5B, upper panel), SOX9 expression only became detectable in XY Nedd4-/- gonads at 24ts and, while the number of SOX9 positive Sertoli cells increased in the 12 hours to 30ts (Fig. 5B, lower panel), this was insufficient to induce the testicular programme in XY Nedd4-/- gonads (Fig. 2). Quantification of Sox9 by RT-qPCR confirmed the lower expression levels, with significantly lower levels of Sox9 transcript at both $11.5 \mathrm{dpc}$ and $12.5 \mathrm{dpc}$ in XY Nedd4-/- compared to XY control gonads, but not as low as $X X$ control gonads (Fig. $5 E$ ).

We sought to further characterise the $X Y$ sex reversal by analysing the expression of $\mathrm{AMH}$, a known target of SOX9 in the developing testis [29, 30], and FOXL2, the ovarian granulosa cell marker [31, 32] by section immunofluorescence from 21 ts to $13.5 \mathrm{dpc}$ (Fig. 5C). While AMH was detected as early as 24 ts in $\mathrm{XY}$ controls, AMH was absent from XX controls, as expected, and XY Nedd4-/- gonads at all stages analysed (Fig. 5C) indicating that the level of SOX9 in Nedd4 ablated gonads was insufficient to induce the expression of $\mathrm{AMH}$. Similarly, FOXL2 expression in developing XY Nedd4-/- gonads was reminiscent of that of XX controls, with few FOXL2 positive cells detectable at $21 \mathrm{ts}$, and subsequently increased in numbers throughout the gonads at later stages (Fig. 5C).

Interestingly, Fox/2 transcripts were significantly higher in $\mathrm{XY}$ Nedd4-/- gonads than in both $\mathrm{XY}$ and $\mathrm{XX}$ controls at $11.5 \mathrm{dpc}$ (Fig. 5F), a potential cause for the gonadal sex reversal later observed in these mice. However, Foxl2 expression was not significantly higher than in XX control gonads at $12.5 \mathrm{dpc}$ (Fig. 5F). Together, these data suggest that an early failure to sufficiently promote the testis-determining programme during a critical time window, and a concurrent upregulation of the ovary-determining pathway, underlies the sex reversal observed in XY Nedd4-/- mice.

\section{Impaired proliferation and reduced $\mathrm{Nr} 5 \mathrm{a} 1$ expression in Nedd4-/- mice}

Given the prevailing size reduction in Nedd4 mutant gonads, we next analysed the proliferative capacity of the coelomic epithelium, which gives rise to supporting and steroidogenic precursors in the developing gonads [33, 34]. This was achieved by coimmunolabelling mutant and control gonads at $11.5 \mathrm{dpc}$ with the proliferation marker MKI67 and GATA4, the earliest known marker of gonadal somatic cells [1]. We found a marked reduction in the number of proliferative somatic cells (GATA4 positive/MKI67 positive) throughout the genital ridge, including within the coelomic epithelium (Fig. 6A, arrowheads), in XY Nedd4-/- mice compared to $X Y$ controls. NEDD4 has been shown to control animal growth through the regulation of insulin and IGF1 signalling via the adaptor protein GRB10 [21]. To investigate if the same mechanism could function in the genital ridge, we interrogated our single-cell RNAseq dataset [35] for co-expression of NEDD4 and known interacting proteins including GRB10 [21] in $X X$ and $X Y$ coelomic epithelial (CE), pre-supporting and supporting-like cells (SLC [35]), all marked by the expression of Nr5a1 and Gata4, at 10.5 and $11.5 \mathrm{dpc}$ (Fig. 6B). While genes encoding for some of the NEDD4 interacting proteins such as Pten, Arrdc3 and Irs 1 are only expressed at very low levels in these cells, Nedd4 was co-expressed with Grb10 and Igf1r (Fig. 6B). Given that proliferation has been shown to be an early determinant of the male fate in embryonic gonads [36], defective proliferation of the genital ridges, likely due to inhibition of insulin and/or IGF1 signalling by GRB10, may contribute to the sex reversal observed in Nedd4-/- mice.

Finally, given that $\mathrm{Nr} 5 a 1$ gene expression is significantly reduced in several mouse models displaying $X Y$ sex reversal phenotypes [37-40], we assessed whether Nr5a1 expression was impacted in XY Nedd4-/- mice by using RT-qPCR at $11.5 \mathrm{dpc}$ and $12.5 \mathrm{dpc}$. Indeed, XY Nedd4-/- mice showed a near 50\% reduction in Nr5a1 levels at $11.5 \mathrm{dpc}$ (Fig. 6B) which may contribute to the reduction in Sox9 transcript levels in Nedd4-/- mice, owing to the known role of NR5A1 in the promotion of Sox9 expression [4]. The reduction in $\mathrm{Nr} 5 \mathrm{a} 1$ transcripts was only transient, however, as expression levels were comparable to controls at $12.5 \mathrm{dpc}$ (Fig. 6B).

\section{DISCUSSION}

Here we report an unexpected and novel role for the ubiquitin ligase NEDD4 in mammalian sex determination with Nedd4-/- mice exhibiting complete male-to-female gonadal sex reversal. This is likely due to a reduction in gonadal precursor cell proliferation due to regulation of insulin and IGF1 signalling by NEDD4 and its interacting protein GRB10, and therefore an early failure to initiate the testis-determining programme which leads to the ectopic expression of the ovarian transcription factor FOXL2.

Expression of $\mathrm{Nr} 5 \mathrm{a1}$, one of the earliest known markers of the developing genital ridges [1], was greatly diminished in gonads of $\mathrm{XY}$ Nedd4-/- mice (Fig. 6B). This is consistent with previously reported mouse models that displayed reduced $\mathrm{Nr} 5 \mathrm{a} 1$ expression and $X Y$ gonadal sex reversal including Six1/4, Insr/lgf1r and Cbx2deficient mice [38-40]. Similarly, all three of these mouse models exhibited a reduction in proliferation of somatic cell progenitors in-line with the reduction observed in Nedd4/- gonads. Given that the Nr5a1 positive cell population resides in the coelomic epithelium and proliferates to give rise to gonadal somatic cells $[33,41]$, and perturbations to this process result in $X Y$ gonadal sex reversal [36], our results implicate NEDD4 in the formation and proliferation of somatic precursors in the developing gonad. Indeed, NEDD4 has been shown to promote proliferation in a range of biological contexts [42-44] and, as such, it is unsurprising that such a role be ascribed to NEDD4 in the developing gonads. Using a proteomics approach, we recently identified the NEDD4interactome, including NEDD4 candidate substrates, in a murine testis cell line [26]. The FunRich Biological process analysis of this dataset revealed cell cycle, cell division and positive regulation of cell proliferation and differentiation to be among the top biological processes identified for NEDD4-mediated regulation [26] and, as such, some of these substrates may contribute to the phenotype observed in Nedd4-deficient mice. The most likely avenue through which NEDD4 could promote genital ridge proliferation is via modulation of insulin and IGF1 signalling in conjunction with GRB10. Indeed, signalling through IGF1R and IR has been shown to be greatly reduced in Nedd4-/- mice, owing to the misregulation of GRB10 [21]. These proteins have been shown to interact in testicular cell lines [26] and we show here that they are co-expressed with NEDD4 in coelomic epithelial, supporting precursor and supporting-like cells in 10.5 and $11.5 \mathrm{dpc}$ genital ridges. Moreover, insulin signalling itself has been shown to be important for testis determination [40], hence it is plausible that a 

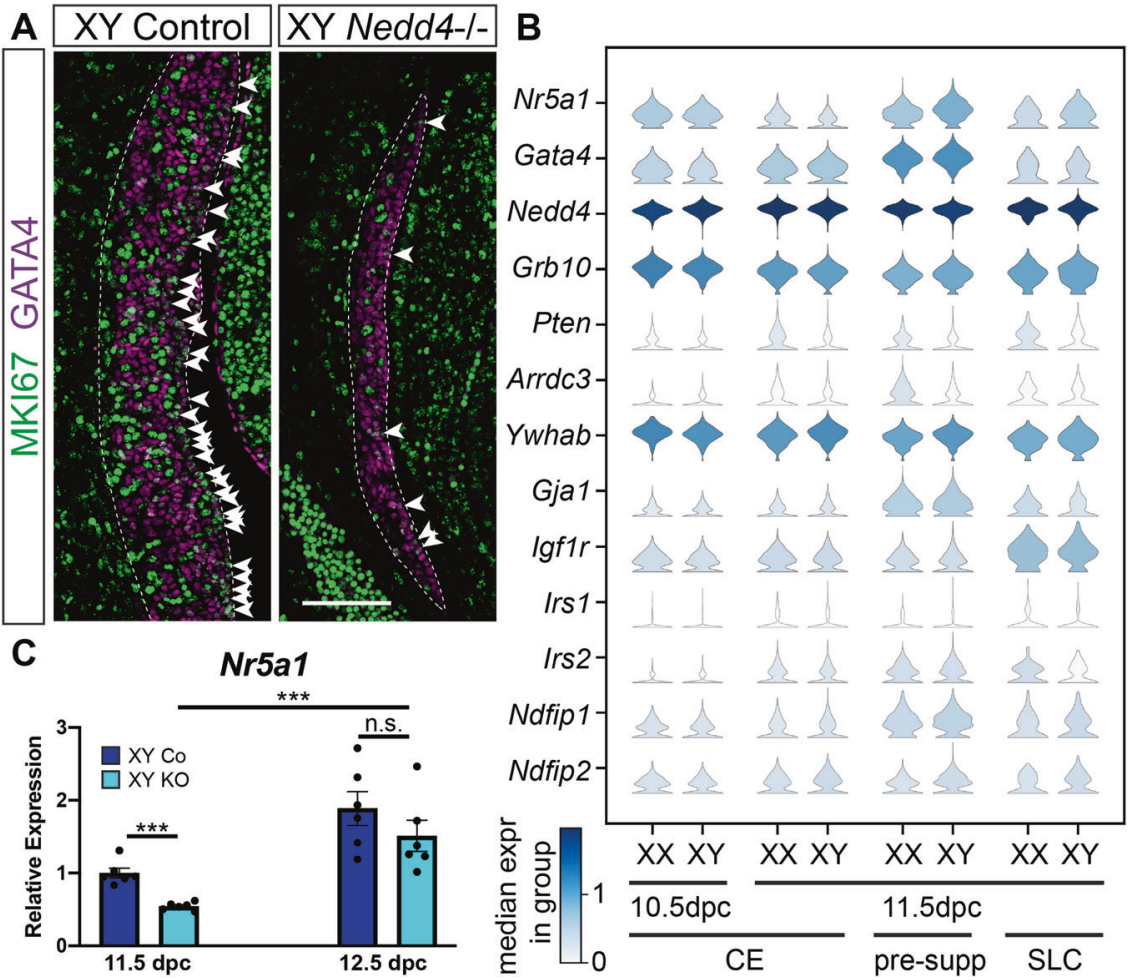

Fig. 6 Impaired proliferation and decreased Nr5a1 expression in XY Nedd4-/- mice. A Section immunofluorescence on 11.5 dpc (18 tail somites [ts]) XY Nedd4-/- embryos and XY controls stained for gonadal somatic cell marker GATA4 (magenta) and proliferation marker MKI67 (green). The anterior pole of each gonad is positioned at the top of each panel. Gonads are denoted by a white dotted line. MKI67-positive cells within the coelomic epithelium are highlighted by white arrowheads. Scale bar $=100 \mu \mathrm{m}$. B Violin plots showing the expression of gonadal progenitor markers Nr5a1 and Gata4 as well as Nedd4 and Nedd4 interacting proteins in mouse gonadal cells expressing both Nr5a 1 and Gata4 at E10.5 and E11.5. XX and XY expression levels are shown separately. Expression levels are shown in log-normalised counts. Colour indicates median expression in the group according to the scale shown in the left bottom corner. CE coelomic epithelium, pre-supp presupporting cells, SLC supporting-like cells. C RT-qPCR analyses of Nr5a1 at $11.5 \mathrm{dpc}$ (17-19ts, gonads + mesonephroi) and $12.5 \mathrm{dpc}$ (30ts, gonads only) on XY Nedd4-/- gonads (KO) (light blue; $n=6$ ) and XY controls (Co) (dark blue; $n=6)$. Values are expressed relative to 11.5 dpc XY controls. Mean \pm SEM; $t$-test; n.s. not significant, ${ }^{* * *} p<0.001$.

reduction in signalling through IGF1R and IR contributes to the gonadal phenotype observed in these mice.

The reduced proliferation of somatic cells in Nedd4-deficient genital ridges likely results in the delay of Sry expression [36]. Sry must act in a critical time window to promote the testicular fate $[45,46]$ as first shown by experiments in mice using a combination of a $Y$ chromosome from some Mus domesticus subspecies, such as Mus domesticus poschiavinus $\left(\mathrm{Y}^{\mathrm{POS}}\right)$, with the inbred $\mathrm{C} 57 \mathrm{BL} / 6$ genetic background [47], and further defined using a transgenic mouse line with an inducible Sry transgene [45]. In these mouse models, a delay in Sry expression results in a reduction in Sox9 levels and subsequent male-to-female sex reversal, which is also observed in XY Nedd4-/- gonads. In addition, reduced Nr5a1 in gonads at this time further compounds the sex reversal observed in these mice, owing to the synergistic roles of SRY and NR5A1 in the promotion of Sox9 transcription [4]. Furthermore, NEDD4 may also directly regulate the expression of Sox9, as Sox9 transcript and protein levels have been shown to be significantly reduced upon knockdown of Nedd4 in vitro, albeit in neural crest cell lines [22].

Given the known binding of SOX9 to the Fox/2 promoter [48] and the ectopic expression of FOXL2 in the absence of Sox9 [49] it is reasonable to argue that the mere absence of SOX9 is sufficient to explain the ectopic expression of FOXL2 observed in XY Nedd4-/mice. However, if this were the only cause, one may anticipate similar expression levels of FoxI2 in XY Nedd4-/- gonads and XX controls. In contrast, Foxl2 transcript levels exceed that seen in XX controls, suggesting that the increase in Fox/2 is partly independent of SOX9 in Nedd4-/- gonads. Given that ectopic FOXL2 expression has been shown to repress Sertoli cell differentiation and reduce
Sox9 levels in XY gonads $[9,12]$ it is possible that this further enforces the sex reversal observed in these mice.

Interestingly, while the gonadal phenotype in XY Nedd4-deficient mice mimicked the one in $X Y$ gonads from mice with deletion of the insulin receptors, the phenotype in XX gonads did not [40]. In Insr; lgfir mutant gonads ovarian differentiation, including germ cell entry into meiosis, was delayed irrespective of the genetic sex [40]. In contrast, the timing of ovarian differentiation in both $X X$ and $X Y$ Nedd4-/- mice appeared to be normal. Accordingly, there was no significant difference in the expression of genes associated with entry into meiosis such as Stra8, Pou5f1 and Cyp26b1 between gonads from $\mathrm{XX}$ wildtype and both XX and XY Nedd4-/- mice at $14.5 \mathrm{dpc}$, further corroborating the notion that ovarian somatic cells differentiated normally, given that the somatic environment drives the development and differentiation of the germline [50, 51]. Surprisingly, expression of the meiotic marker gene Sycp3 was significantly higher in both XX and XY Nedd4-/- gonads when compared to both XX and $X Y$ littermate controls. It is unknown, however, whether this is indicative of a germ cell-intrinsic role for NEDD4 or a consequence of the role of NEDD4 in the surrounding somatic cells. Interestingly, NEDD4 has been shown to interact with both NANOS2 and DAZL in spermatogonial stem cells, germ cell derivatives in the postnatal testis [52]. As both NANOS2 and DAZL have been implicated in regulating meiosis and germ cell differentiation during foetal development $[53,54]$ it is likely that the same interactions between these two proteins and NEDD4 exist in the developing gonads and interrogating the influence of the loss of NEDD4 on these two substrates may prove fruitful in furthering our understanding of the role of this enzyme in the developing germ cells. 
Together, our findings highlight an unexpected novel role for the ubiquitin-protein ligase NEDD4 in gonadal sex determination and gonad development, with the loss of Nedd4 resulting in maleto-female gonadal sex reversal. These results provide possible evidence for a hitherto unrecognised role of this enzyme in human idiopathic XY DSDs.

\section{MATERIALS AND METHODS Mouse lines}

Nedd4-/- mice, described previously [21], were backcrossed for at least seven generations onto the inbred C57BL/6 strain, obtained from the Animal Resources Centre (Western Australia). Nedd4-/- embryos were generated by timed matings of Nedd4+/- parents, with noon of the day on which a mating plug was observed deemed as 0.5 days post coitum (dpc). For more accurate staging of embryos up to $12.5 \mathrm{dpc}$, the tail somite stage (ts) was determined by counting the number of somites posterior to the hind limb, with 18ts corresponding to $11.5 \mathrm{dpc}$, 24ts corresponding to 12.0 $\mathrm{dpc}$ and 30ts corresponding to $12.5 \mathrm{dpc}$ [55]. Genotyping at the Nedd4 locus was performed on genomic DNA derived from tail tissue using the following primer combinations: Nedd4_Geno_WT_F: 5'-TCTTATGGGTGCTG TGGTTACAG-3' and Nedd4 Geno R: 5'-CATGTGCTITACCACTGAGC-3' for the wildtype allele and Nedd4_Geno_KO_F: 5'-CCTTGCAAAATGGCGTTACT-3' and Nedd4_Geno_R: 5'-CATGTGCTTACCACTGAGC-3' for the mutant allele [22]. Genetic sex was determined by PCR as described before [56]. For NEDD4 expression studies, embryos were collected from timed matings of wildtype C57BL/6. All animals obtained that had the required genotype were included in the analyses.

\section{Immunofluorescence}

Section immunofluorescence on paraformaldehyde-fixed, paraffinembedded mouse embryos was performed as described previously [26] Each analysis was performed on at least three independent biological samples. Primary antibodies used were rabbit anti-SOX9 (ref. [3]) (1:200), goat anti-DDX4 (R\&D Systems, RDSAF2030) (1:300), rabbit anti-CYP11A1 (ref. [57]) (1:300), goat anti-AMH (Santa Cruz, sc6886) (1:300), rabbit anti-FOXL2 (ref. [58]) (1:300), mouse anti-SYCP3 (Abcam, ab97672) (1:100), rabbit anti-SRY [3] (1:100), goat anti-GATA4 (Santa Cruz, sc1237) (1:300), mouse anti-Ki67 (BD Transduction Lab, 550609) (1:100) and mouse anti-NEDD4 (BD Transduction Laboratories, 611481) (1:100). All secondary antibodies were purchased from Invitrogen and were used at a dilution of 1:300. These include donkey antimouse Alexa 488 (A21202), donkey anti-rabbit Alexa 488 (A21202), donkey anti-goat 546 (A11056) and donkey anti-mouse Alexa 647 (A31571).

\section{Quantitative real-time RT-PCR (RT-qPCR)}

Embryonic gonads were dissected from the underlying mesonephros for all embryonic stages, except $11.5 \mathrm{dpc}$ where the complex remained intact, and snap-frozen in liquid nitrogen. Total RNA was isolated using Trizol (Ambion) and single-stranded CDNA synthesised using the Protoscript II First Strand cDNA Synthesis Kit (New England Biolabs). qPCR was performed with the SensiFAST SYBR No-ROX Kit (Bioline) using the Rotor-Gene 3000 system (Qiagen). Primers used can be found in Supplementary Table 1. Relative mRNA levels were normalised to Sdha and are shown relative to controls as indicated in the Figure legends. Each reaction was performed in technical triplicate and each experiment was performed with at least three biological replicates. Error bars represent the standard error of the mean (SEM) between biological replicates. Statistical significance between groups was determined using a two-tailed, unpaired Student's $t$-test.

\section{Single-cell RNAseq analysis}

Single-cell isolation, collection, sequencing, data preprocessing and annotation were performed as described [35]. Cells annotated as coelomic epithelium, early supporting-like cells and pre-supporting cells from 10.5 and $11.5 \mathrm{dpc}$ were isolated and a Leiden clustering was applied with 0.2 resolution. Five clusters were obtained and one cluster with a mean expression of $\mathrm{Nr} 5 \mathrm{a} 1$ and Gata4 below 0.1 was excluded. In total 7407 cells were kept.

\section{DATA AVAILABILITY}

The datasets generated and/or analysed during the current study are available from the corresponding author on reasonable request.

\section{REFERENCES}

1. Hu YC, Okumura LM, Page DC. Gata4 is required for formation of the genital ridge in mice. PLoS Genet. 2013;9:e1003629.

2. Bullejos $M$, Koopman P. Spatially dynamic expression of Sry in mouse genital ridges. Developmental Dyn. 2001;221:201-5.

3. Wilhelm D, Martinson F, Bradford S, Wilson MJ, Combes AN, Beverdam A, et al. Sertoli cell differentiation is induced both cell-autonomously and through prostaglandin signaling during mammalian sex determination. Dev Biol. 2005;287:111-24.

4. Sekido R, Lovell-Badge R. Sex determination involves synergistic action of SRY and SF1 on a specific Sox9 enhancer. Nature. 2008;453:930-4.

5. Chaboissier MC, Kobayashi A, Vidal VI, Lutzkendorf S, van de Kant HJ, Wegner M, et al. Functional analysis of Sox8 and Sox9 during sex determination in the mouse. Development. 2004;131:1891-901.

6. Barrionuevo F, Bagheri-Fam S, Klattig J, Kist R, Taketo MM, Englert C, et al. Homozygous inactivation of Sox9 causes complete XY sex reversal in mice. Biol Reprod. 2006;74:195-201.

7. Koopman P, Gubbay J, Vivian N, Goodfellow P, Lovell-Badge R. Male development of chromosomally female mice transgenic for Sry. Nature. 1991;351:117-21.

8. Vidal VP, Chaboissier MC, de Rooij DG, Schedl A. Sox9 induces testis development in XX transgenic mice. Nat Genet. 2001;28:216-7.

9. Nicol B, Grimm SA, Gruzdev A, Scott GJ, Ray MK, Yao HH. Genome-wide identification of FOXL2 binding and characterization of FOXL2 feminizing action in the fetal gonads. Hum Mol Genet. 2018;27:4273-87.

10. Maatouk DM, DiNapoli L, Alvers A, Parker KL, Taketo MM, Capel B. Stabilization of beta-catenin in $\mathrm{XY}$ gonads causes male-to-female sex-reversal. Hum Mol Genet. 2008;17:2949-55.

11. Ottolenghi C, Omari S, Garcia-Ortiz JE, Uda M, Crisponi L, Forabosco A, et al. Foxl2 is required for commitment to ovary differentiation. Hum Mol Genet. 2005;14:2053-62.

12. Uhlenhaut NH, Jakob S, Anlag K, Eisenberger T, Sekido R, Kress J, et al. Somatic sex reprogramming of adult ovaries to testes by FOXL2 ablation. Cell. 2009;139:1130-42.

13. Windley SP, Wilhelm D. Signaling pathways involved in mammalian sex determination and gonad development. Sex Dev. 2015;9:297-315.

14. Callier $P$, Calvel $P$, Matevossian A, Makrythanasis $P$, Bernard $P$, Kurosaka $H$, et al. Loss of function mutation in the palmitoyl-transferase HHAT leads to syndromic $46, \mathrm{XY}$ disorder of sex development by impeding Hedgehog protein palmitoylation and signaling. PLoS Genet. 2014;10:e1004340.

15. Harris A, Siggers P, Corrochano S, Warr N, Sagar D, Grimes DT, et al. ZNRF3 functions in mammalian sex determination by inhibiting canonical WNT signaling. Proc Natl Acad Sci USA. 2018;115:5474-9.

16. Rossitto M, Déjardin S, Rands CM, Gras SL, Migale R, Rafiee M-R, et al. TRIM28dependent SUMOylation protects the adult ovary from the male pathway. bioRxiv: 2021.2003.2024.436749. 2021. https://doi.org/10.1101/2021.03.24.436749.

17. Kerscher $O$, Felberbaum R, Hochstrasser M. Modification of proteins by ubiquitin and ubiquitin-like proteins. Annu Rev Cell Dev Biol. 2006;22:159-80.

18. Kumar S, Tomooka $Y$, Noda M. Identification of a set of genes with developmentally down-regulated expression in the mouse brain. Biochem Biophys Res Commun. 1992;185:1155-61.

19. Kumar S, Harvey KF, Kinoshita M, Copeland NG, Noda M, Jenkins NA. cDNA cloning, expression analysis, and mapping of the mouse Nedd4 gene. Genomics. 1997;40:435-43.

20. Rotin D, Kumar S. Physiological functions of the HECT family of ubiquitin ligases. Nat Rev Mol Cell Biol. 2009;10:398-409.

21. Cao XR, Lill NL, Boase N, Shi PP, Croucher DR, Shan H, et al. Nedd4 controls animal growth by regulating IGF-1 signaling. Sci Signal. 2008;1:ra5.

22. Wiszniak S, Kabbara S, Lumb R, Scherer M, Secker G, Harvey N, et al. The ubiquitin ligase Nedd 4 regulates craniofacial development by promoting cranial neural crest cell survival and stem-cell like properties. Dev Biol. 2013;383:186-200.

23. Yang B, Gay DL, MacLeod MK, Cao X, Hala T, Sweezer EM, et al. Nedd4 augments the adaptive immune response by promoting ubiquitin-mediated degradation of Cbl-b in activated T cells. Nat Immunol. 2008;9:1356-63.

24. Liu Y, Oppenheim RW, Sugiura Y, Lin W. Abnormal development of the neuromuscular junction in Nedd4-deficient mice. Dev Biol. 2009;330:153-66.

25. Fouladkou F, Lu C, Jiang C, Zhou L, She Y, Walls JR, et al. The ubiquitin ligase Nedd4-1 is required for heart development and is a suppressor of thrombospondin-1. J Biol Chem. 2010;285:6770-80.

26. Manning J, Windley SP, Sandow JJ, Shah SS, Western P, Wilhelm D, et al. Identification of novel interacting partners of the NEDD4 ubiquitin ligase in mouse testis. J Proteom. 2020;223:103830.

27. Bowles J, Knight D, Smith C, Wilhelm D, Richman J, Mamiya S, et al. Retinoid signaling determines germ cell fate in mice. Science. 2006;312:596-600.

28. Koubova J, Menke DB, Zhou Q, Capel B, Griswold MD, Page DC. Retinoic acid regulates sex-specific timing of meiotic initiation in mice. Proc Natl Acad Sci USA. 2006;103:2474-9. 
29. De Santa Barbara P, Bonneaud N, Boizet B, Desclozeaux M, Moniot B, Sudbeck P, et al. Direct interaction of SRY-related protein SOX9 and steroidogenic factor 1 regulates transcription of the human anti-Mullerian hormone gene. Mol Cell Biol. 1998;18:6653-65.

30. Arango NA, Lovell-Badge R, Behringer RR. Targeted mutagenesis of the endogenous mouse Mis gene promoter. Cell. 1999;99:409-19.

31. Loffler KA, Zarkower D, Koopman P. Etiology of ovarian failure in blepharophimosis ptosis epicanthus inversus syndrome: FOXL2 is a conserved, early-acting gene in vertebrate ovarian development. Endocrinology. 2003;144:3237-43.

32. Schmidt D, Ovitt CE, Anlag K, Fehsenfeld S, Gredsted L, Treier AC, et al. The murine winged-helix transcription factor Foxl2 is required for granulosa cell differentiation and ovary maintenance. Development. 2004;131:933-42.

33. Karl J, Capel B. Sertoli cells of the mouse testis originate from the coelomic epithelium. Dev Biol. 1998;203:323-33.

34. Stevant I, Kuhne F, Greenfield A, Chaboissier MC, Dermitzakis ET, Nef S. Dissecting cell lineage specification and sex fate determination in gonadal somatic cells using single-cell transcriptomics. Cell Rep. 2019;26:3272-83.

35. Mayère $C$, Regard V, Perea-Gomez A, Bunce $C$, Neirijnck $Y$, Djari $C$, et al. Origin, specification and differentiation of a rare supporting-like lineage in the developing mouse gonad. bioRxiv. 2021. https://doi.org/10.1101/2021.09.15.460431.

36. Schmahl J, Capel B. Cell proliferation is necessary for the determination of male fate in the gonad. Dev Biol. 2003;258:264-76.

37. Buaas FW, Val P, Swain A. The transcription co-factor CITED2 functions during sex determination and early gonad development. Hum Mol Genet. 2009;18:2989-3001.

38. Katoh-Fukui Y, Miyabayashi K, Komatsu T, Owaki A, Baba T, Shima Y, et al. Cbx2, a polycomb group gene, is required for Sry gene expression in mice. Endocrinology. 2012;153:913-24.

39. Fujimoto $Y$, Tanaka SS, Yamaguchi YL, Kobayashi H, Kuroki S, Tachibana M, et al. Homeoproteins Six 1 and Six4 regulate male sex determination and mouse gonadal development. Dev Cell. 2013;26:416-30.

40. Pitetti JL, Calvel P, Romero Y, Conne B, Truong V, Papaioannou MD, et al. Insulin and IGF1 receptors are essential for $X X$ and $X Y$ gonadal differentiation and adrenal development in mice. PLoS Genet. 2013;9:e1003160.

41. Schmahl J, Eicher EM, Washburn LL, Capel B. Sry induces cell proliferation in the mouse gonad. Development. 2000;127:65-73.

42. Huang ZJ, Zhu JJ, Yang XY, Biskup E. NEDD4 promotes cell growth and migration via PTEN/PI3K/AKT signaling in hepatocellular carcinoma. Oncol Lett. 2017;14:2649-56.

43. Li Y, Zhang L, Zhou J, Luo S, Huang R, Zhao C, et al. Nedd4 E3 ubiquitin ligase promotes cell proliferation and autophagy. Cell Prolif. 2015;48:338-47.

44. Fukushima $T$, Yoshihara $H$, Furuta $H$, Kamei $H$, Hakuno $F$, Luan J, et al. Nedd4induced monoubiquitination of IRS-2 enhances IGF signalling and mitogenic activity. Nat Commun. 2015;6:6780.

45. Hiramatsu R, Matoba S, Kanai-Azuma M, Tsunekawa N, Katoh-Fukui Y, Kurohmaru $M$, et al. A critical time window of Sry action in gonadal sex determination in mice. Development. 2009;136:129-38.

46. Wilhelm D, Washburn LL, Truong V, Fellous M, Eicher EM, Koopman P. Antagonism of the testis- and ovary-determining pathways during ovotestis development in mice. Mech Dev. 2009;126:324-36.

47. Eicher EM, Washburn LL, Whitney JB,3rd, Morrow KE. Mus poschiavinus Y chromosome in the C57BL/6J murine genome causes sex reversal. Science. 1982;217:535-7.

48. Rahmoun M, Lavery R, Laurent-Chaballier S, Bellora N, Philip GK, Rossitto M, et al. In mammalian foetal testes, SOX9 regulates expression of its target genes by binding to genomic regions with conserved signatures. Nucleic Acids Res. 2017;45:7191-211.

49. Georg I, Barrionuevo F, Wiech T, Scherer G. Sox9 and Sox8 are required for basal lamina integrity of testis cords and for suppression of FOXL2 during embryonic testis development in mice. Biol Reprod. 2012;87:99.

50. Adams IR, McLaren A. Sexually dimorphic development of mouse primordial germ cells: switching from oogenesis to spermatogenesis. Development. 2002;129:1155-64.

51. McLaren A, Southee D. Entry of mouse embryonic germ cells into meiosis. Dev Biol. 1997;187:107-13.

52. Zhou Z, Kawabe H, Suzuki A, Shinmyozu K, Saga Y. NEDD4 controls spermatogonial stem cell homeostasis and stress response by regulating messenger ribonucleoprotein complexes. Nat Commun. 2017;8:15662.

53. Lin Y, Gill ME, Koubova J, Page DC. Germ cell-intrinsic and -extrinsic factors govern meiotic initiation in mouse embryos. Science. 2008;322:1685-7.

54. Suzuki A, Saga Y. Nanos 2 suppresses meiosis and promotes male germ cell differentiation. Genes Dev. 2008;22:430-5.
55. Hacker A, Capel B, Goodfellow P, Lovell-Badge R. Expression of Sry, the mouse sex determining gene. Development. 1995;121:1603-14.

56. McFarlane L, Truong V, Palmer JS, Wilhelm D. Novel PCR assay for determining the genetic sex of mice. Sex Dev. 2013;7:207-11.

57. Svingen $T$, Francois $M$, Wilhelm $D$, Koopman $P$. Three-dimensional imaging of Prox1-EGFP transgenic mouse gonads reveals divergent modes of lymphangiogenesis in the testis and ovary. PLoS ONE. 2012;7:e52620.

58. Cocquet J, Pailhoux E, Jaubert F, Servel N, Xia X, Pannetier M, et al. Evolution and expression of FOXL2. J Med Genet. 2002;39:916-21.

\section{ACKNOWLEDGEMENTS}

The authors would like to thank the staff of the University of Melbourne's Biomedical Sciences Animal facility for mouse colony maintenance and animal husbandry, the University of Melbourne's Biological Optical Microscopy Platform for use of their confocal microscopes and the Melbourne Histology Platform for tissue processing. The authors would also like to thank Drs. Stefan Bagheri-Fam and Catherine Sterling for fruitful discussions pertaining to this project. This work was supported by an Australian Research Council Discovery Grant (150101448) to DW and SK. SK was supported by a National Health and Medical Research Council of Australia grants (GNT 1103006 and GNT2007739).

\section{AUTHOR CONTRIBUTIONS}

SPW, CM, SN, SK and DW designed the experiments. SPW and CM conducted experiments. SPW and DW wrote the paper. All authors revised and commented on the manuscript. AEM, NLH and QS provided helpful comments and discussion. DW and SK oversaw the project and acquired funding.

\section{ETHICS STATEMENT}

All animal experiments were performed with the approval of the Anatomy and Physiology Animal Ethics Committee of the University of Melbourne (approval number 1513725).

\section{COMPETING INTERESTS}

The authors declare no competing interests.

\section{ADDITIONAL INFORMATION}

Supplementary information The online version contains supplementary material available at https://doi.org/10.1038/s41419-022-04519-z.

Correspondence and requests for materials should be addressed to Dagmar Wilhelm.

Reprints and permission information is available at http://www.nature.com/reprints

Publisher's note Springer Nature remains neutral with regard to jurisdictional claims in published maps and institutional affiliations.

(i) Open Access This article is licensed under a Creative Commons Attribution 4.0 International License, which permits use, sharing, adaptation, distribution and reproduction in any medium or format, as long as you give appropriate credit to the original author(s) and the source, provide a link to the Creative Commons license, and indicate if changes were made. The images or other third party material in this article are included in the article's Creative Commons license, unless indicated otherwise in a credit line to the material. If material is not included in the article's Creative Commons license and your intended use is not permitted by statutory regulation or exceeds the permitted use, you will need to obtain permission directly from the copyright holder. To view a copy of this license, visit http://creativecommons. org/licenses/by/4.0/.

(c) Crown 2022 